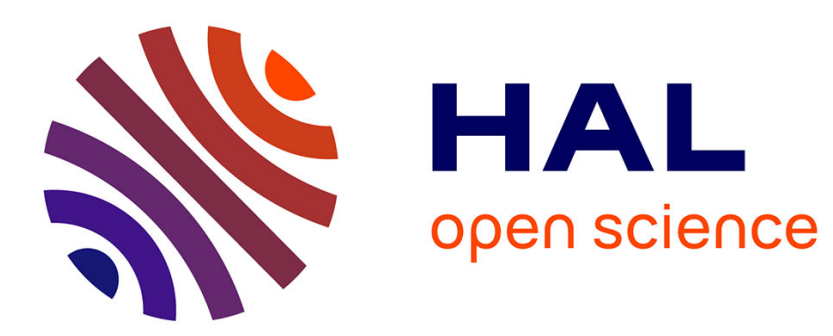

\title{
GISAXS - Glancing incidence small angle X-ray scattering
}

J. Levine Parrill, P. Georgopoulos, Y.-W. Chung, J. Cohen

\section{To cite this version:}

J. Levine Parrill, P. Georgopoulos, Y.-W. Chung, J. Cohen. GISAXS - Glancing incidence small angle X-ray scattering. Journal de Physique IV Proceedings, 1993, 03 (C8), pp.C8-411-C8-417. 10.1051/jp4:1993885 . jpa-00252316

\section{HAL Id: jpa-00252316 https://hal.science/jpa-00252316}

Submitted on 1 Jan 1993

HAL is a multi-disciplinary open access archive for the deposit and dissemination of scientific research documents, whether they are published or not. The documents may come from teaching and research institutions in France or abroad, or from public or private research centers.
L'archive ouverte pluridisciplinaire HAL, est destinée au dépôt et à la diffusion de documents scientifiques de niveau recherche, publiés ou non, émanant des établissements d'enseignement et de recherche français ou étrangers, des laboratoires publics ou privés. 


\title{
GISAXS - Glancing incidence small angle X-ray scattering
}

\author{
J.R. LEVINE PARRILL, P. GEORGOPOULOS*, Y.-W. CHUNG* and J.B. COHEN* \\ IBM, East Fishkill, EM1, Route 52, Hopewell Junction, NY 12533, U.S.A. \\ * Department of Materials Science and Engineering, McCormick School of Engineering and Applied \\ Science, Northwestern University, Evanston, IL 60208, U.S.A.
}

\begin{abstract}
In this method, the incident beam is totally externally reflected from a surface or substrate, followed by small-angle scattering of the refracted (evanescent) beam by the surface region. As one example, GISAXS can provide size information on islands associated with film growth. The technique is described, along with examples from studies of $\mathrm{Au}$ on glass, and InAs on silicon. In contrast to TEM this technique is nondestructive, can be done in situ, provides excellent sampling, does not necessarily require synchrotron radiation, and is not limited to thin or conducting substrates.
\end{abstract}

\section{INTRODUCTION}

The basic experimental arrangement, first discussed in 1988 [1], is illustrated in Fig. 1. Because $x$-rays have an index of refraction slightly less than unity, there is total external reflection, at low angles of incidence (a few mrad). As well as the reflected beam, there is a refracted beam which at the critical angle for reflection, travels along the surface and penetrates only a few tens of Angstroms, Fig. 2: for this reason it is referred to as an evanescent wave. This evanescent wave can act as a source for diffraction from near surface regions, as first demonstrated by Marra, Eisenberger and Cho in 1979 [2], for wideangle diffraction from planes perpendicular to a film surface.

This surface wave can be a source for small angle scattering and is particularly useful for parameterizing islands in thin film growth. In this paper, after discussing some special features of this method, we give examples of Au islands on glass, and InAs forming on $\mathrm{Si}$. For further details, see references [3-5]. The method was actually discovered about the same time as our group by Naudon and coworkers [6]. Their use was to examine clustering near surfaces, as compared to the bulk.

\section{The Technique}

The experimental arrangement, using a position sensitive detector, is illustrated in Fig. 3, where it is seen that the detector is carefully positioned to avoid the reflection and beam spillover.

There are several points in the theory of small angle scattering that need consideration. The usual equation for small angle scattering, Eq. 1, needs modification: 


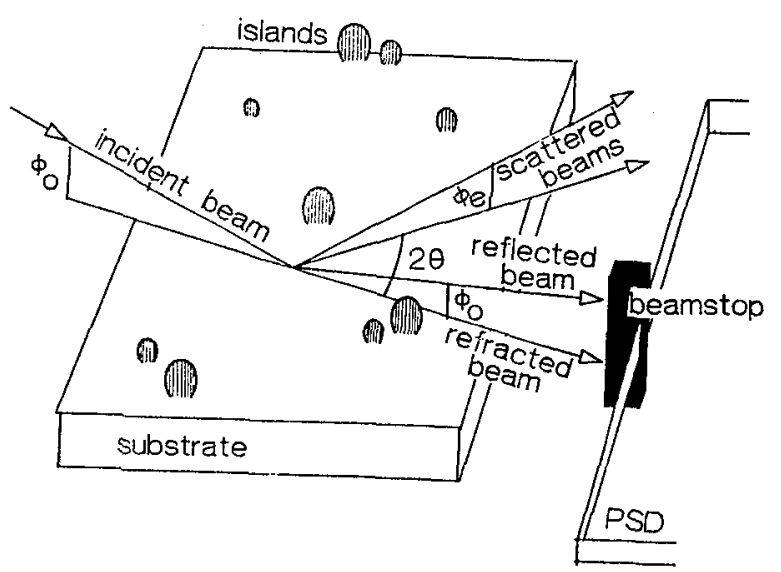

Figure 1. Experimental scattering geometry for GISAXS. The angle $2 \theta$ is measured in the plane of the sample surface. The angles $\phi_{0}$ are in a plane perpendicular to the sample surface. The position sensitive detector (PSD) is parallel to the surface. The refracted beam illuminates surface features which produce SAXS at $0^{\circ}<2 \theta<4^{\circ}$.

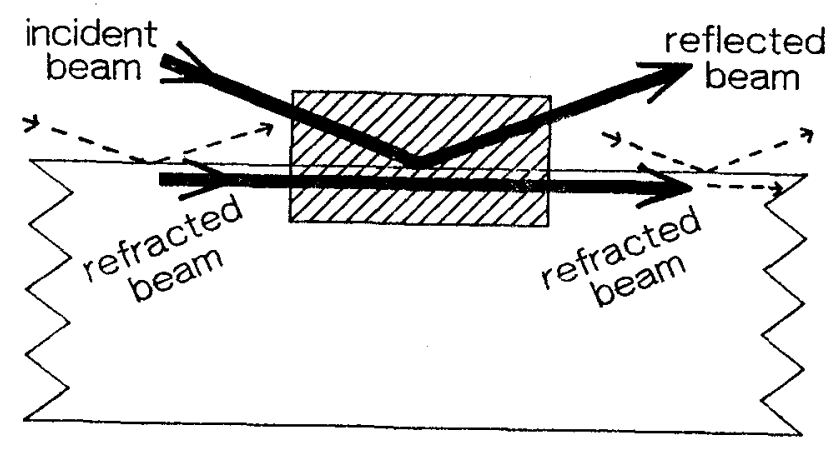

Figure 2. Dotted rays indicate reflection/refraction reactions occur all along infinite surface having islands.

$$
I_{S A X S}(h)=I_{e}(h)\left(\Delta \rho_{e}\right)^{2} t_{i} N_{V} e^{-\mu t} \Sigma_{R} V_{p}^{2}(R) \Phi^{2}(h R) Z(R)
$$

In this equation, $t$ is the sample thickness, $A_{i}$ the irradiated area, and $N_{V}$ the number of particles per unit volume and the other terms have their usual meaning. The product $t A_{j} N_{V}$ becomes $A_{i} N_{a}$ where $N_{a}$ is the number of scattering regions per unit area. For the absorption $e^{-\mu t}, t$ is the refracted beam penetration, $L$ and with $\phi$ the incident angle:

$$
L=\frac{\lambda}{2 \pi\left(\phi_{c}^{2}-\phi^{2}\right)^{1 / 2}}
$$




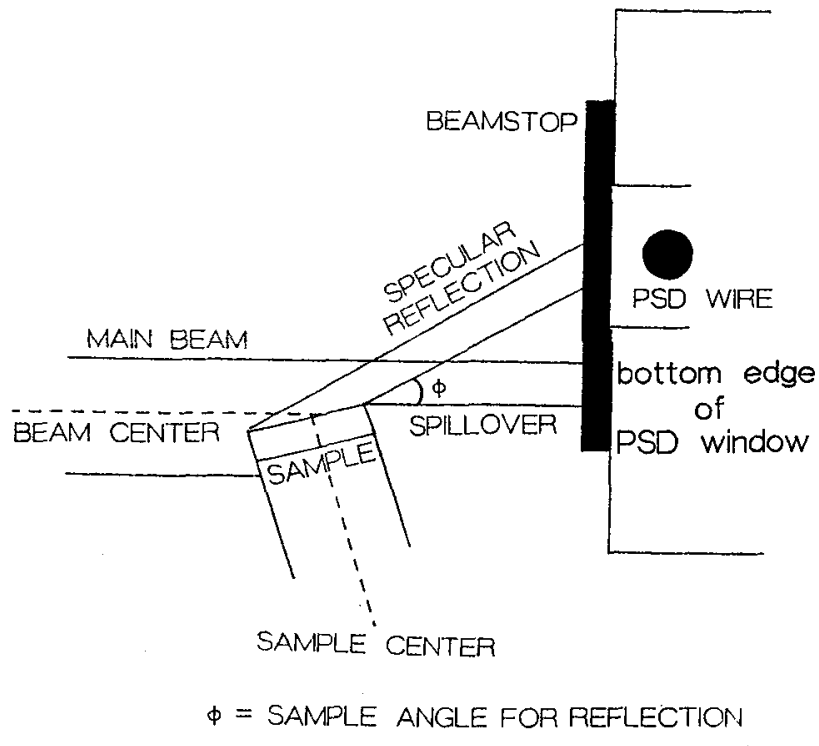

Figure 3. Configuration of incident beam spillover, PSD, specular reflection, beamstop, and sample for correct GISAXS alignment.

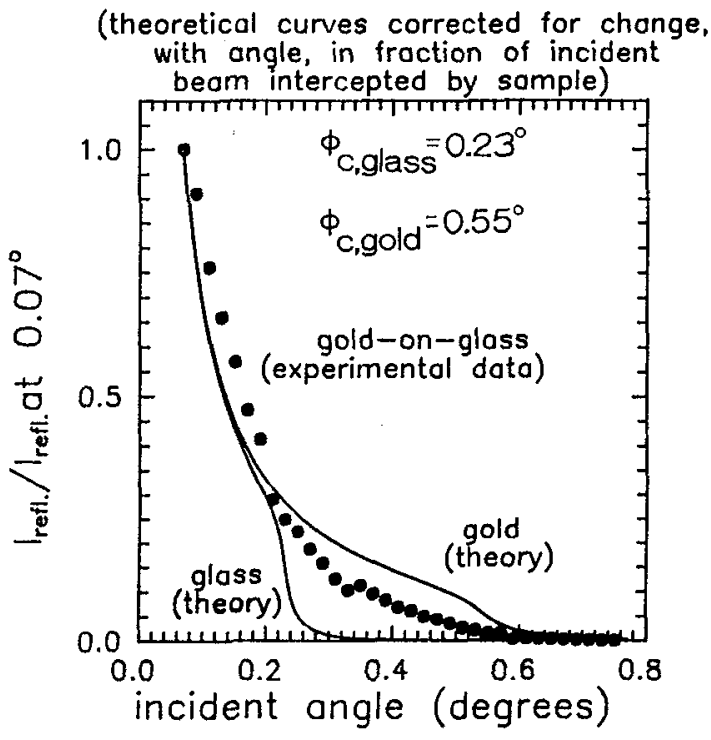

Figure 4. Dots are reflected intensity as a function of incident angle from a gold on glass sample with a $40 \%$ gold coverage. Solid curves are the variations with angle of the theoretical reflectivity coefficients. 
where the critical angle, $\phi_{C}$ is:

$$
\phi_{\mathrm{c}}=\lambda\left(\frac{\rho_{\mathrm{e}} r_{\mathrm{e}}}{\pi}\right)^{1 / 2}
$$

The term $I_{0}$ becomes $f I_{\text {refr: }}$ were $f$ is fraction of the refracted beam intercepted, and:

$$
\begin{aligned}
& I_{\text {refr }}=\frac{4 \phi^{2}}{\left(\phi_{c}+p\right)^{2}+q^{2}} \\
& p^{2}-q^{2}=\phi^{2}-\phi_{C}^{2} \\
& p q=\beta \\
& \beta=\mu \lambda / 4 \pi
\end{aligned}
$$

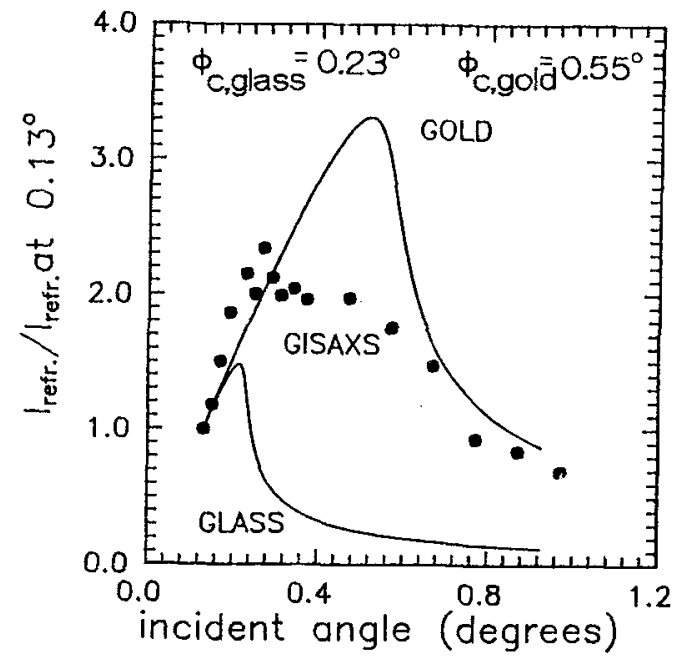

Figure 5. Dots are GISAXS intensity as a function of incident angle at $h=0.05 \AA^{-1}$ from a gold on glass sample with a $40 \%$ gold coverage. Solid curves are the variations with angle of the evanescent wave for gold and glass. Theoretical intensities are corrected for fraction of incident beam intercepted. Optimum GISAXS intensity is obtained near the critical angle for glass.

If we take as an example, Au islands $(\approx 24 \AA$ in radius) on glass, Fig. 4 illustrates the measured reflectivity (points) and those calculated (solid line), and similarly for the refracted wave, Fig. 5 . It is clear that both the islands and the glass contribute, but as the islands are only $24 \AA$ thick in this case and there is only $40 \%$ coverage, the refracted wave from the Au passes along the glass as well.

Figure 6 illustrates that in a reflection geometry the source of scattering covers dimensions much larger than the usual micron or so sample thickness in transmission 
SAXS. With the detector at a distance of several hundred $\mathrm{mm}$, there is no significant distortion of the scattering [5].

\section{Gold on Glass [4.5]}

Typical patterns are given in Fig. 7 for average film thicknesses of 5,9 and $13 \AA$. At these coverages (up to $40 \%$ ) there is strong interparticle interference in the scattering, and there is no Guinier region. Nevertheless, the Porod radius (or the surface to volume ratio) can be determined, and from the peak in the scattering, the interparticle distance. Size comparisons with TEM reveal that the particles are hemispherical and from fractal analysis they are smooth.

The patterns are actually two dimensional. Fig. 8 is a digitized film of the pattern, on one side of the direct beam, and above the sample. From the data normal to the film the size in that direction may also be determined and such results indicated that the particles are slightly flattened.

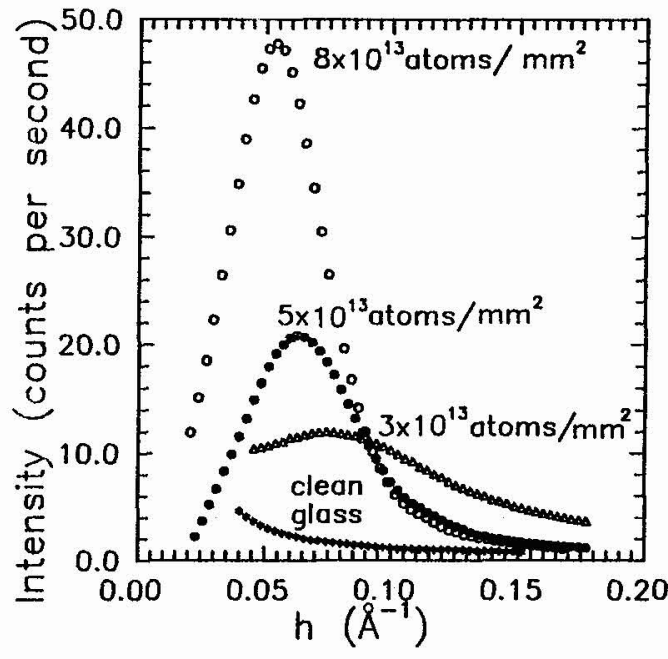

Figure 7. GISAXS data for three gold films with different average thicknesses; scattering from clean glass included for reference.

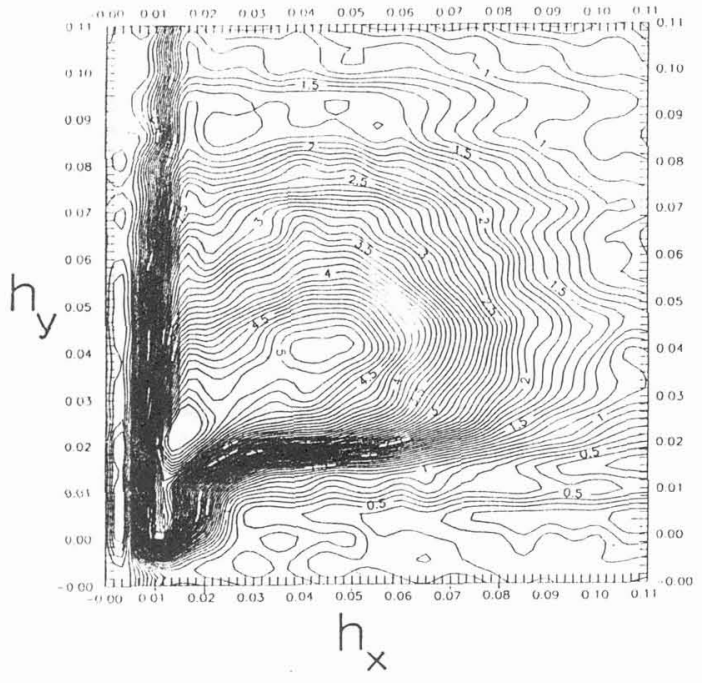

Figure 8. Topographic map of two-dimensional GISAXS pattern from Au islands.

In ref. 4, kinetic data were taken during deposition (in a UHV environment), and in situ, after annealing for various times and temperatures. The particles grew in size and decreased in number by soft impingement, diffusion-limited mobile island growth [4]. The activation energy and diffusion coefficient for the process are of the same magnitude as values for single-atom surface diffusion. Coarsening models (which predict a power law dependence on time, $\mathrm{t}^{1 / \mathrm{n}}$ ) are not adequate.

\section{InAs on Si (5)}

As another example, InAs films were prepared in UHV by C. H. Choi [7], using low energy ion beam bombardment assisted molecular beam epitaxy. Sample 1 contains 30 
monolayers of InAs, 2 has 16 , and 3, 15. For No. 1 the arsenic cell was at $593^{\circ} \mathrm{K}$ and the ion beam was $30 \mathrm{eV}$, for No. $2,613^{\circ} \mathrm{K}$ and $15 \mathrm{eV}$ and for No. $3,613^{\circ} \mathrm{K}$ and $30 \mathrm{eV}$. The samples one and three have rounded islands, whereas in 2 , there were facets.

The scattering patterns are shown in Fig. 9, and the Porod plots in Fig. 10. (The Guinier regions are behind the beam stop). The sizes are of the order of $50 \AA \hat{\text {. }}$

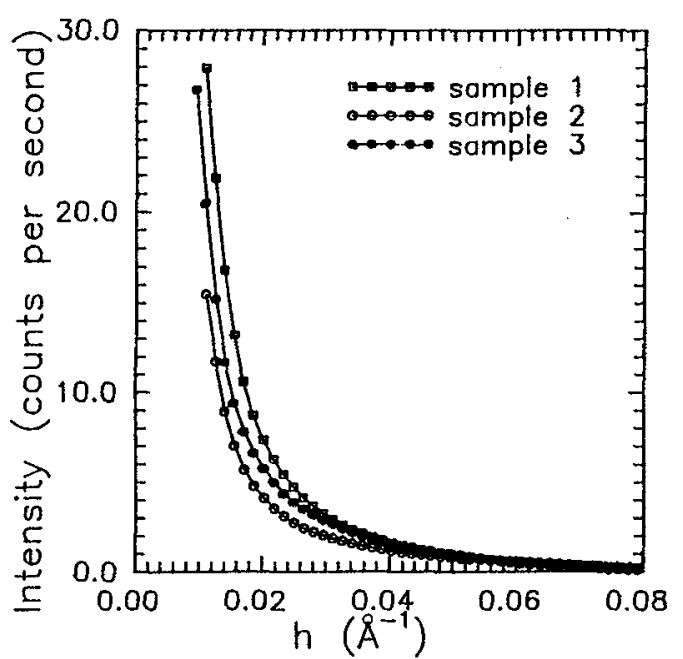

Figure 9. GISAXS data for three InAs films on $\mathrm{Si}$ substrates. InAs has layer plus island morphology.

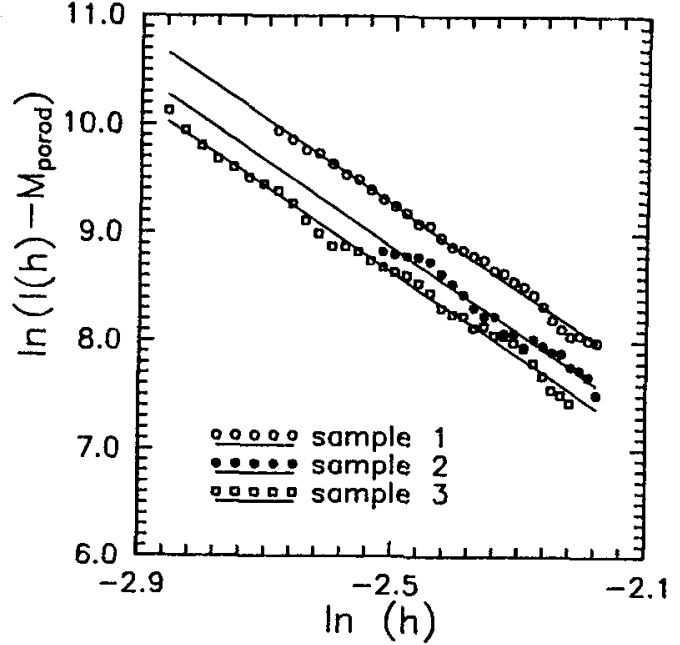

Figure 10. Porod plots for InAs/Si samples. Slopes are approximately -4 and data has been corrected for background contributions by substracting slopes of power Porod plots.

\section{ACKNOWLEDGEMENTS}

This research was funded by MATRIX (the Midwest Associated Team for Research in Intense X-rays) through DOE contract No. De-FG02-85-ER45183. A005. The authors thank Dr. P. Georgopoulos for advice and assistance and Dr. C. H. Choi for growing the InAs films. This research is part of a thesis submitted (by J. R. L. P.) in partial fulfillment of the requirements for the Ph.D. degree at Northwestern University.

\section{REFERENCES}

[1] Levine, J.R., Y.W.Chung, Cohen, J.B. and Georgopoulos, P., J. Vac. Sci. Technol., A6(3) (1988) 1771.

[2] Marra, W.C., Eisenberger, P. and Cho, A.Y., J. Appl. Phys., 50 (1979) 6927.

[3] Levine, J.R., Cohen, J. B., Chung, Y.W. and Georgopoulos, J. Appl. Cryst., 22 (1989) 528. 
[4] Levine, J.R., Cohen, J. B. and Chung, Y.W., Surface Science, 248 (1991) 215.

[5] Levine, J.R., Ph.D. Thesis, Northwestern University, 1990.

[6] Naudon, A., Slimani, T. and Goudeau, P., J. Appl. Cryst., 24 (1991) 501.

[7] Choi, C.H., Huttman, L. and Barnett, S.A., J. Vac. Sci. Technol., A8 (1990) 1587. 